\title{
Association of antithyroglobulin antibody with iodine nutrition and thyroid dysfunction in Nepalese children
}

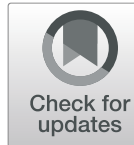

Binaya Tamang ${ }^{1}$, Saroj Khatiwada ${ }^{2 *} \mathbb{D}$, Basanta Gelal ${ }^{3}$, Shrijana Shrestha ${ }^{3}$, Kishun Deo Mehta ${ }^{3}$, Nirmal Baral ${ }^{3}$, Gauri Shankar Shah ${ }^{4}$ and Madhab Lamsal ${ }^{3}$

\begin{abstract}
Background: Aberrant iodine intake and thyroid autoimmunity affect thyroid function. Deficiencies of iodine including thyroid disorders have serious impact on child physical and mental development. This study was conducted to investigate iodine nutrition, thyroid function and thyroid autoimmunity in the Nepalese children, and explore the association of thyroidal autoimmunity with iodine nutrition and thyroid dysfunction.

Methods: Five schools from Udayapur district of eastern Nepal were selected for the study. A total of 213 school children aged 6-12 years were enrolled, and anthropometric data, urine samples and blood samples were collected. Urinary iodine concentration (UIC), free triiodothyronine (fT3), free thyroxine (fT4), thyroid stimulating hormone (TSH), and antithyroglobulin antibody (TgAb) was measured. Independent T test, Man-Whitney test, Chi-square test and Fisher's Exact test were used for testing statistical significance. Spearman's correlation analysis was done to find association between variables.
\end{abstract}

Results: The median UIC with IQR, mean \pm SD fT3, mean \pm SD fT4, median TSH and TgAb with IQR was $150.0 \mu \mathrm{g} / \mathrm{L}$ (102.8; 204.0), $2.49 \pm 0.83 \mathrm{pg} / \mathrm{ml}, 1.33 \pm 0.42 \mathrm{ng} / \mathrm{dl}, 2.49 \mathrm{mIU} / \mathrm{L}(1.58 ; 4.29)$, and $21.40 \mathrm{IU} / \mathrm{ml}(15.54 ; 31.20)$ respectively. Elvated $\operatorname{TgAb}(\geq 30 \mathrm{IU} / \mathrm{ml}$, thyroid autoimmune condition) was seen in $25.8 \%(n=55)$ children. UIC was less than $100 \mu \mathrm{g} / \mathrm{L}$ in $17.4 \%(n=37)$ of the children. Subclinical hypothyroidism, overt hypothyroidism and sublinical hyperthyroidism was seen in 1.4\% $(n=3), 3.3 \%(n=7)$ and $3.8 \%(n=8)$ children respectively. A strong association of TgAb with UIC ( $r=-0.210, p=0.002)$ and thyroid hormones; fT3 ( $r=-0.160, p=0.019)$, fT4 $(r=-0.275, p<0.001)$, and TSH $(r=0.296, p<0.001)$ was seen. The relative risk for thyroid autoimmunity in children with UIC less than $100 \mu \mathrm{g} / \mathrm{L}$ was 1.784 (95\% Cl: 1.108-2.871, $p=0.024$ ). Similarly, children with thyroid autoimmunity had higher relative risk [7.469 (95\% Cl: 2.790-19.995, $p<0.001)]$ for thyroid dysfunction.

Conclusions: School children of eastern Nepal have adequate iodine nutrition. Thyroid autoimmunity is very common, while thyroid dysfunction is sparse in children. An association of thyroid autoimmunity with iodine nutrition and thyroid dysfunction was seen in children.

Keywords: Antithyroglobulin antibody, lodine deficiency, Nepal, School children, Thyroid autoimmunity, Thyroid dysfunction

\footnotetext{
* Correspondence: khatiwadasaroj22@gmail.com

${ }^{2}$ School of Medical Sciences, UNSW SYDNEY, Sydney, Australia

Full list of author information is available at the end of the article
}

(c) The Author(s). 2019 Open Access This article is distributed under the terms of the Creative Commons Attribution 4.0 International License (http://creativecommons.org/licenses/by/4.0/) which permits unrestricted use, distribution, and reproduction in any medium, provided you give appropriate credit to the original author(s) and the source, provide a link to the Creative Commons license, and indicate if changes were made. The Creative Commons Public Domain Dedication waiver (http://creativecommons.org/publicdomain/zero/1.0/) applies to the data made available in this article, unless otherwise stated. 


\section{Background}

Thyroid gland produces hormones essential for normal growth and development of the body. Deficiency of thyroid hormones, a condition called as hypothyroidism, or excess of thyroid hormones called as hyperthyroidism, both alter normal body physiology and metabolism $[1,2]$. The prevalence of thyroid dysfunction ranges from 1 to $10 \%$ among adults from general population, however, prevalence varies across different groups [3]. In Nepal, high prevalence of thyroid disorders has been reported among patients visiting tertiary hospitals, and those with chronic diseases [4-7]. Several studies have shown thyroid dysfunction to be common among pregnant women and school children of eastern Nepal [8-10].

The most common cause of thyroid disorders worldwide is iodine deficiency except in the areas with adequate iodine nutrition where thyroid autoimmunity is the major cause [11]. Severe iodine deficiency causes hypothyroidism, while at the same time excessive iodine intake can also negatively impact thyroid function [12]. In addition, the development of autoantibodies against thyroid proteins mainly thyroid peroxidase (TPO), thyroglobulin (Tg), and thyroid stimulating hormone (TSH) receptor can lead to thyroid disorders [13]. Aberrant iodine intake can play a crucial role in the development of thyroid autoimmunity, and affect the rate of thyroid diseases [14]. There is less information regarding thyroid autoimmunity in Nepalese children.

In the past, iodine deficiency used to be a significant health problem in Nepal, but ever since universal salt iodization program (USI) was initiated in 1993, iodine deficiency disorders have progressively dropped [15]. Our studies among the school children of eastern Nepal show good improvement in iodine nutrition as indicated by rising median urinary iodine concentration (UIC) of the population over the past years, which is consistent with the increasing usage of adequately iodized salt by the households [16-19]. Because of the risk associated with excess or inadequate iodine intake, it is important to monitor iodine intake and iodine nutrition in the population.

Our previous studies were focused on iodine nutrition, iron status, thyroid function and their relationships in the children $[9,10,17]$. In this study, we aimed to evaluate iodine nutrition, thyroid function and thyroid autoimmunity including their relationship in the school children from eastern Nepal.

\section{Methods}

This cross-sectional study was conducted by the Department of Biochemistry in collaboration with department of Pediatrics and Adolescent Medicine of B. P. Koirala Institute of Health Sciences (BPKIHS), Dharan, Nepal in the Udayapur district of eastern Nepal in the year 2015-
2016. Udayapur district has a mixed geography comprising plain (low altitude) and hilly (high altitude) areas. Three village development committee (VDC); Katunjebawala, Chaudandi and Siddhipur were selected for the current study. One VDC (Katunjebawala) lies at low altitude of around $306 \mathrm{~m}$ above the sea level whereas the other two (Chaudandi and Siddhipur) lie at high altitude, around $2300 \mathrm{~m}$ above the sea level. Those VDCs were selected randomly as a representative of low and high altitude regions of Udayapur district. A total of five schools (two from Katunjebawala, one from Chaudandi and two from Siddhipur) were chosen for the subject recruitment. From each school, children aged 6-12 years were enrolled. Prior to the enrollment, the objectives and benefits of the study were explained to the school authorities including guardians and participants of the study. Consent to participate in the study was taken from each child and their guardian. Participants taking micronutrient supplements, with severe illness and those not willing to participate were excluded from the study. The ethical clearance for this study was provided by the Institutional Review Committee (IRC) of BPKIHS.

Two hundred thirteen children participated in the study. The sample size was estimated based on assumption of approximate prevalence of iodine deficiency (ID) (15\%), thyroid dysfunction (20\%), and thyroid autoimmunity (15\%) in the Nepalese population. From each subject anthropometric data (height, weight) was recorded, and then urine and blood samples were collected at the same time. Casual urine samples were collected in $10 \mathrm{ml}$ sterile tubes and blood samples $(2 \mathrm{ml})$ in plain vials. Serum was separated within an hour of blood collection. Urine and serum samples were transported to the biochemistry laboratory of BPKIHS maintaining cold chain and stored at $-20^{\circ} \mathrm{C}$ until analyte measurement. UIC was estimated in the urine samples using ammonium persulfate digestion microplate (APDM) method (based on Sandell-Kolthoff reaction), in a specially designed apparatus, sealing cassette [20]. In the serum, free tri-iodothyronine (fT3), free tetra-iodothyronine (fT4), thyroid stimulating hormone (TSH) and antithyroglobulin antibody $(\mathrm{TgAb})$ were measured. Thyroid hormones; fT3, fT4 and TSH were measured by ELISA method using commercial kits from Diametra Company. TgAb was estimated by chemiluminescence immunoassay (CLIA) method using MAGLUMI 1000 CLIA kits.

The reference ranges provided by the kits manufacturer for fT3, fT4, TSH, and TgAb were $1.4-4.2 \mathrm{pg} / \mathrm{ml}$, $0.8-2.2 \mathrm{ng} / \mathrm{dL}, 0.39-6.16 \mathrm{mIU} / \mathrm{L}$, and $<30 \mathrm{IU} / \mathrm{ml}$ respectively. Using above reference ranges, children were classified for thyroid autoimmunity (thyroid autoimmunity if $\mathrm{TgAb} \geq 30 \mathrm{IU} / \mathrm{ml}$, no thyroid autoimmunity if $\mathrm{TgAb}<30$ $\mathrm{IU} / \mathrm{ml}$ ) and thyroid function status (euthyroid, overt and subclinical hypothyroid, and subclinical hyperthyroid). 
Iodine status was classified as insufficient (UIC $<100 \mu \mathrm{g} /$ L) or sufficient (UIC $\geq 100 \mu \mathrm{g} / \mathrm{L}$ ) iodine nutrition based on UIC cutoff $100 \mu \mathrm{g} / \mathrm{L}$, and as severe ID, moderate ID, mild ID, sufficient and excessive iodine nutrition based on WHO criteria [21, 22].

The data was entered in MS excel and analyzed by SPSS version 20.2 software after checking for the normality using Shapiro-Wilk test. The data were expressed as mean \pm SD or median with interquartile range (IQR). Independent $\mathrm{T}$ test, Man-Whitney test, Chi-square test and Fisher's Exact test were used for testing statistical significance at $95 \%$ confidence interval. For measuring the association among variables, Spearman's correlation analysis was done. The relative risk for thyroid autoimmunity in children with insufficient UIC as compared to those with sufficient UIC, relative risk for thyroid dysfunction in children with insufficient UIC and thyroidal autoimmunity as compared to those with sufficient UIC and non-thyroidal immunity respectively was calculated at $95 \%$ confidence interval. A $p$ value $<0.05$ was considered statistically significant.

\section{Results}

\section{Anthropometric measurements}

The data were collected from 213 children, 66 were from low altitude (VDC: Katunjebawala) and 115 from high altitude (VDCs: Chaudandi and Siddhipur). The mean \pm SD age, height and weight of the children were $10.2 \pm 1.7$ years, $125.9 \pm 9.5 \mathrm{~cm}$ and $25.4 \pm 5.7 \mathrm{~kg}$ respectively. The mean \pm SD age, height and weight in the children from low altitude were $10.5 \pm 1.6$ years, $128.0 \pm 8.4 \mathrm{~cm}$ and $26.8 \pm 4.6 \mathrm{~kg}$ respectively. Among the children from high altitude, mean age, height and weight was $10.1 \pm 1.8$ years, $124.9 \pm 9.9 \mathrm{~cm}$ and $24.8 \pm$ $6.0 \mathrm{~kg}$ respectively. The number of males and females in the study was 115 and 98 respectively. The mean \pm SD age, height and weight was $10.4 \pm 1.7$ years, $126.2 \pm 10.0 \mathrm{~cm}$ and $25.3 \pm 5.3 \mathrm{~kg}$ respectively in boys. In girls, the mean \pm SD age, height and weight was $10.1 \pm 1.7$ years, $\quad 125.5 \pm 8.9 \mathrm{~cm}$ and $25.5 \pm 6.1 \mathrm{~kg}$ respectively.

\section{UIC, thyroid hormones and anti-Tg antibodies levels}

As shown in Table 1 , median UIC with IQR, mean \pm SD fT3, mean \pm SD fT4, median TSH and TgAb with IQR were $150.0 \mu \mathrm{g} / \mathrm{L}$ (102.8; 204.0), $2.49 \pm 0.83 \mathrm{pg} / \mathrm{ml}, 1.33 \pm$ $0.42 \mathrm{ng} / \mathrm{dl}, 2.49 \mathrm{mIU} / \mathrm{L}(1.58 ; 4.29)$, and $21.40 \mathrm{IU} / \mathrm{ml}$ $(15.54 ; 31.20)$ respectively. Median UIC was significantly higher in males than females $(p=0.03)$, and in the children from high altitude than low altitude $(p=0.002)$. Median $\operatorname{TgAb}$ was significantly higher in the children from low altitude than from high altitude $(p=0.036)$. lodine nutrition, thyroid disorders and thyroid autoimmunity Thyroid dysfunction and thyroid autoimmunity $(\mathrm{TgAb} \geq 30 \mathrm{IU} / \mathrm{ml})$ were present in $18(8.5 \%)$ and 55 (25.8\%) children respectively. About 37 (17.4\%) children had UIC $<100 \mu \mathrm{g} / \mathrm{L}$. Based on WHO criteria, severe, moderate, and mild ID was seen in $1(0.5 \%), 8(3.8 \%)$ and $28(13.1 \%)$ children respectively. Iodine nutrition was excessive (UIC $\geq 300 \mu \mathrm{g} / \mathrm{L}$ ) in $21(9.9 \%)$ children. Insufficient iodine nutrition was found in $31.8 \%(n=21)$ of the children from low altitude and $10.9 \% \quad(n=16)$ children from high altitude. Thyroid dysfunction was seen in $6.1 \%(n=4)$ children residing in low altitude and 9.5\% $(n=14)$ children residing in high altitude. Similarly, thyroid autoimmunity was seen in $34.8 \%(n=23)$ children from low altitude and $21.8 \%(n=32)$ from high altitude. Child sex and altitude did not affect thyroid function ( $p=0.419$ and $p=0.888$ respectively). Similarly, child sex did not affect thyroid autoimmunity $(p=0.594)$ and iodine nutrition $(p=0.149)$, but altitude affected thyroid autoimmunity $(p=0.044)$ and iodine nutrition $(p<0.001)$. Type of thyroid dysfunction according to thyroid autoimmunity and iodine nutrition is shown in Table 2.

\section{Relationship of UIC with thyroid hormones and anti-Tg antibodies}

Anthropometric measures were not associated with iodine nutrition, thyroid hormones and thyroid autoantibodies level. The correlation of UIC with TSH, UIC with $\operatorname{TgAb}$, and TgAb with TSH is shown in Figs. 1, 2 and 3 respectively. A strong positive correlation of UIC with fT3 $(\mathrm{r}=0.361, p<0.001)$, and fT4 $(\mathrm{r}=0.365, p<0.001)$ was seen. UIC had negative correlation with TSH $(\mathrm{r}=-$ $0.399, p<0.001)$. TgAb had significant negative correlation with fT3 $(r=-0.160, p=0.019)$, fT4 $(r=-0.275$, $p<0.001)$, UIC $(\mathrm{r}=-0.210, p=0.002)$, and positive with TSH $(r=0.296, p<0.001)$. The relative risk of having thyroid dysfunction in children with thyroid autoimmunity was 7.469 (95\% CI: $2.790-19.995, p<0.001$ ) as compared to children without thyroidal autoimmunity. Similarly, the relative risk for thyroid dysfunction in children with insufficient UIC was 2.378 (95\% CI: 0.954-5.930, $p=0.096$ ) as compared to children with sufficient UIC. The relative risk for thyroid autoimmunity in children with insufficient UIC was 1.784 (95\% CI: $1.108-2.871, p=0.024)$.

\section{Discussion}

This study finds high rate of thyroid autoimmunity and a low rate of thyroid dysfunction in school children of eastern Nepal. Iodine nutrition is adequate in the population with median UIC $150 \mu \mathrm{g} / \mathrm{L}$; however, $17 \%$ children had UIC $<100 \mu \mathrm{g} / \mathrm{L}$. Poor iodine nutrition was found to 
Table 1 Median UIC, thyroid hormones and TgAb in the study population

\begin{tabular}{|c|c|c|c|c|c|c|c|}
\hline \multirow[t]{2}{*}{ Variables } & \multirow[t]{2}{*}{ Total $N=213$} & \multicolumn{3}{|l|}{ Sex } & \multicolumn{3}{|l|}{ Altitude } \\
\hline & & Male $N=115$ & Female $N=98$ & $P$ value & Low altitude $N=66$ & High altitude $N=147$ & $P$ value \\
\hline Median UIC ( $\mu \mathrm{g} / \mathrm{L})$ & $150.0(102.8 ; 204.0)$ & $166.9(105.0 ; 221.0)$ & $150.0(105.0 ; 192.36)$ & 0.03 & $107.5(90.8 ; 186.5)$ & $163.0(108.0 ; 212.0)$ & 0.002 \\
\hline Mean fT3 (pg/ml) & $2.49 \pm 0.83$ & $2.57 \pm 0.79$ & $2.41 \pm 0.87$ & 0.174 & $2.51 \pm 0.85$ & $2.49 \pm 0.82$ & 0.864 \\
\hline Mean fT4 (ng/dl) & $1.33 \pm 0.42$ & $1.31 \pm 0.38$ & $1.37 \pm 0.46$ & 0.289 & $1.28 \pm 0.43$ & $1.36 \pm 0.41$ & 0.186 \\
\hline Median TSH (mIU/L) & $2.49(1.58 ; 4.29)$ & $2.48(1.64 ; 3.79)$ & $2.56(1.44 ; 4.71)$ & 0.412 & $2.75(1.69 ; 4.77)$ & $2.36(1.53 ; 4.06)$ & 0.222 \\
\hline Median TgAb (IU/ml) & $21.40(15.54 ; 31.20)$ & $20.60(14.89 ; 28.92)$ & $21.5(16.76 ; 32.98)$ & 0.217 & $24.65(16.76 ; 41.24)$ & $20.4(15.3 ; 27.98)$ & 0.036 \\
\hline
\end{tabular}

The data are expressed as mean \pm SD or median (IQR). Independent samples T test and Mann-Whitney test was applied for testing statistical significance

be associated with thyroid autoimmunity and thyroid dysfunction.

Thyroid disorders are the second most common endocrine disorder worldwide [11]. In this study, thyroid dysfunction was seen in $8.5 \%$ of the children. Subclinical hyperthyroidism (3.8\%) was the most common thyroid disorders followed by subclinical hypothyroidism (3.3\%) and overt hypothyroidism (1.4\%). Previous study by Chaudhari et al. reported subclinical hypothyroidism in 31.8 and 29.5\% children of Sunsari and Dhankuta districts of eastern Nepal [23]. In another study from eastern Nepal, subclinical hypothyroidism, overt hypothyroidism and subclinical hyperthyroidism was seen in 16.3, 1.3 and $1.8 \%$ children respectively [9]. The main cause of thyroid disorders worldwide is iodine deficiency, except in the areas where iodine intake is sufficient. In such areas, autoimmunity towards thyroidal tissue is the leading cause for thyroid disorder [11].

School children are one of the most vulnerable groups for iodine deficiency. Iodine deficiency is the most common cause of mental retardation worldwide [22]. The median UIC in the present study was $150.0 \mu \mathrm{g} / \mathrm{L} \mu \mathrm{g} / \mathrm{L}$, which indicates adequate iodine nutrition. The median UIC in the children from low altitude and high altitude was $107.5 \mu \mathrm{g} / \mathrm{L}$ and $163.0 \mu \mathrm{g} / \mathrm{L}$ respectively. After the launch of USI in Nepal, iodine nutrition has improved sharply [15]. Other studies by Chaudhari et al. in 2009 reported median UIC of $238.0 \mu \mathrm{g} / \mathrm{L}$ in Dhankuta and $294.9 \mu \mathrm{g} / \mathrm{L}$ in Sunsari, and Shakya et al. in 2010-2011 found median UIC of $345.6 \mu \mathrm{g} / \mathrm{L}$ in Tehrathum and $270.4 \mu \mathrm{g} / \mathrm{L}$ in Morang [10, 23]. Among the study population, $17.4 \%$ of the children had UIC $<100 \mu \mathrm{g} / \mathrm{L}$, which suggest the necessity of monitoring iodine intake in such children. Previously in this region, Gelal et al., Khatiwada et al. and Shakya et al. found iodine deficiency in 22.0, 12.6, and 8.6\% school children respectively $[10,17,24]$. Surprisingly, here we found higher median UIC in the children living in the high altitude than low altitude of the district. Similar trend in the median UIC was seen by Shakya et al. between the plain district (Morang) and hilly district (Tehrathum) [10]. Usually, iodine deficiency is found to be more common in the hilly and mountainous areas possibly due to the low level of iodine in the soil in such areas [25]. Our finding suggests adequate consumption of iodine rich food including iodized salts by the children living in the high altitude of the district.

For determining thyroid autoimmunity status in the children, we estimated TgAb concentration. Based on the $\operatorname{TgAb}$ concentration cutoff, high level of $\operatorname{TgAb}$ was found in $25.8 \%$ children, suggesting a high prevalence of thyroid autoimmunity. Previous data about the prevalence of thyroidal autoimmunity is not available for Nepalese children. In a study from Iran positive $\mathrm{Tg}$ antibodies was present in 5.3\% school children [26]. In Sri Lanka, prevalence of high $\mathrm{TgAb}$ ranging from $14.3 \%$ (in 11 years old) to $69.7 \%$ (in 16 years old) was seen in females after salt iodization was made compulsory, pointing out the potential side effect of excess iodization [27]. In one of the study among Nepalese pregnant women, thyroid autoimmunity as estimated using anti-TPO antibodies was seen in 3.3\% of the women [8]. The common antibodies developed against thyroid include TPO, TSH receptor and $\mathrm{Tg}$

Table 2 Thyroid dysfunction according to autoimmunity and iodine status in the study subjects

\begin{tabular}{|c|c|c|c|c|c|c|c|}
\hline \multirow[t]{2}{*}{ Variables } & \multirow{2}{*}{$\begin{array}{l}\text { Total } \\
\mathrm{N}=213\end{array}$} & \multicolumn{3}{|c|}{ Thyroid autoimmunity } & \multicolumn{3}{|l|}{ lodine status } \\
\hline & & $\begin{array}{l}\mathrm{TgAb}<30 \mathrm{IU} / \mathrm{ml} \\
N=158\end{array}$ & $\begin{array}{l}\text { TgAb } \geq 30 \mathrm{IU} / \mathrm{ml} \\
\mathrm{N}=55\end{array}$ & $P$ value & $\begin{array}{l}\mathrm{UIC}<100 \mu \mathrm{g} / \mathrm{L} \\
\mathrm{N}=37\end{array}$ & $\begin{array}{l}\mathrm{UIC}>100 \mu \mathrm{g} / \mathrm{L} \\
N=176\end{array}$ & $P$ value \\
\hline Euthyroidism, n (\%) & $195(91.5 \%)$ & $153(71.8 \%)$ & $42(19.7 \%)$ & $<0.001$ & $31(14.6 \%)$ & $164(77.0 \%)$ & 0.033 \\
\hline Overt hypothyroidism, n (\%) & $3(1.4 \%)$ & - & $3(1.4 \%)$ & & $1(0.5 \%)$ & $2(0.9 \%)$ & \\
\hline Subclinical hypothyroidism, n (\%) & $7(3.3 \%)$ & - & $7(3.3 \%)$ & & $4(1.9 \%)$ & $3(1.4 \%)$ & \\
\hline Subclinical hyperthyroidism, n (\%) & $8(3.8 \%)$ & $5(2.4 \%)$ & $3(1.4 \%)$ & & $1(0.5 \%)$ & 7 (3.3\%) & \\
\hline
\end{tabular}

The data is expressed as number (percentage). Fisher's Exact Test was applied to test statistical significance 


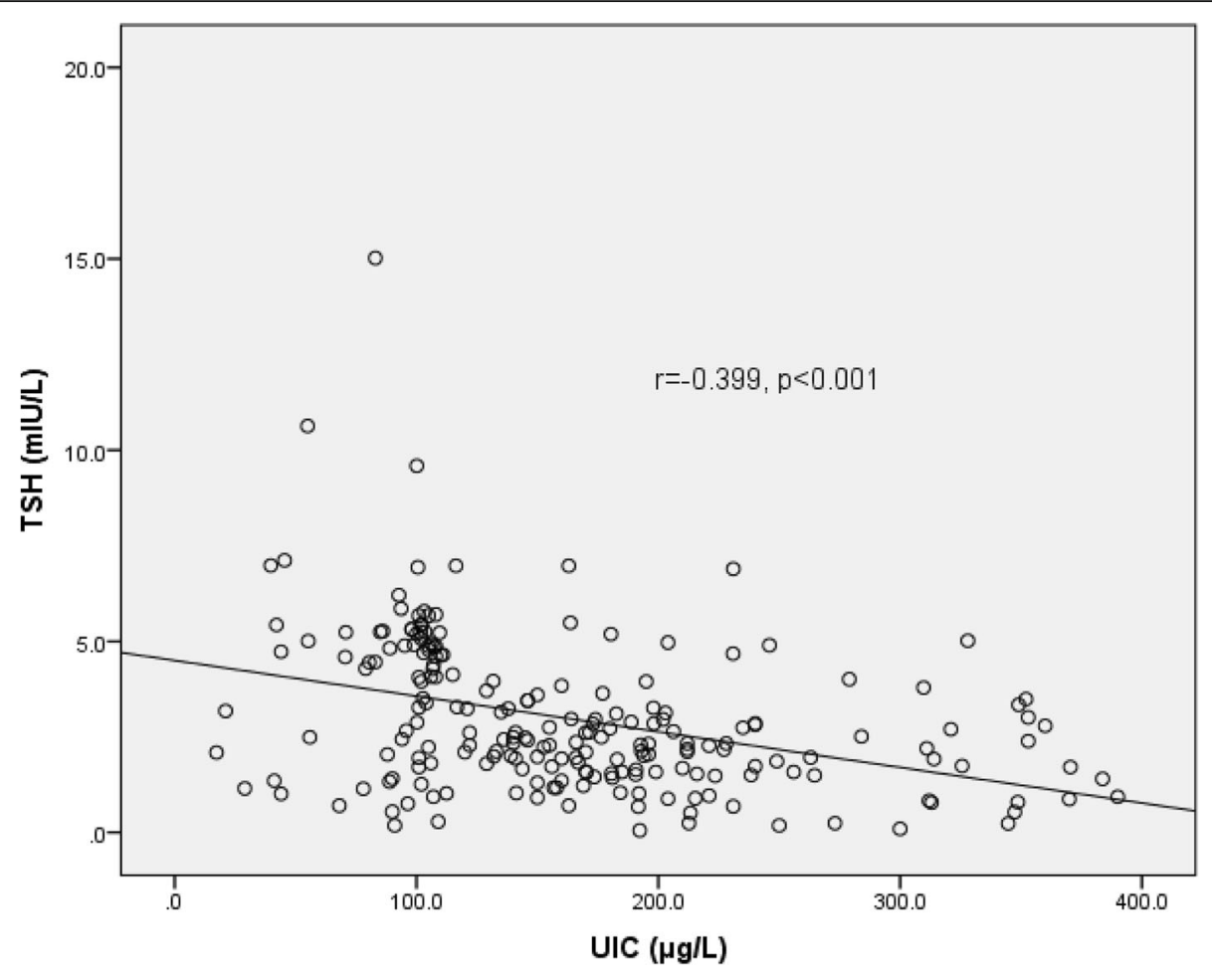

Fig. 1 Correlation of UIC with TSH concentration

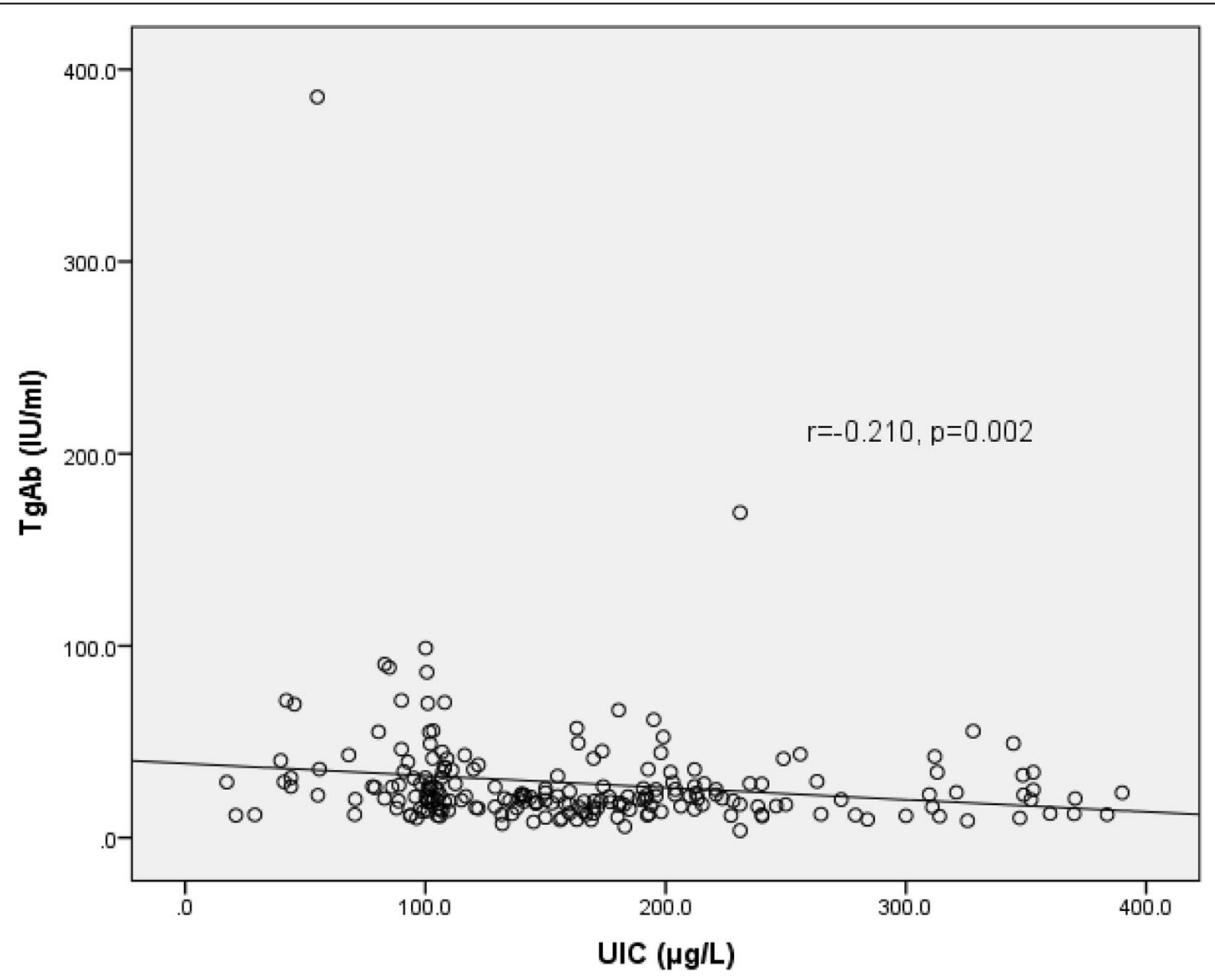

Fig. 2 Correlation of UIC with TgAb concentration 


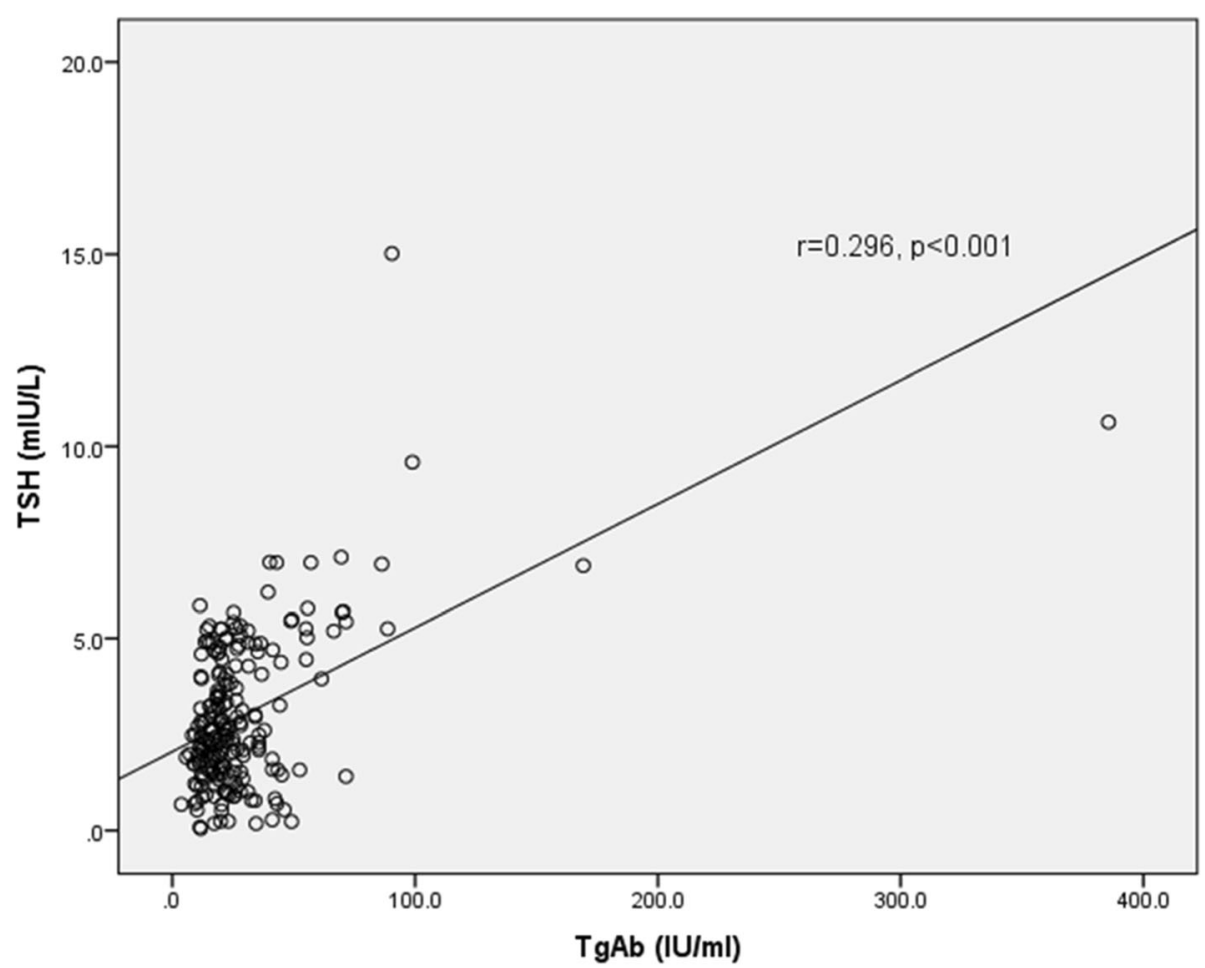

Fig. 3 Correlation of TgAb with TSH concentration

antibodies, and such antibodies when reach a certain threshold concentration will impair thyroid function [13]. Several factors such as genetic makeup, epigenetics factor, dietary pattern, gender, environmental factors such as exposure to toxin, smoking, infection, radiation and medications, and iodine intake can trigger thyroid autoimmunity [28]. Interestingly in this study, thyroid autoimmunity was more common among children living in low altitude than living in high altitude. This might be due to the difference in iodine intake, ethnicity, genetic makeup and sociodemographic status of the children living in different altitude.

In this study, we observed a strong association of UIC with thyroid hormones namely $\mathrm{TSH}$, which suggest a strong role of iodine nutrition on the thyroid function. High UIC indicates excessive iodine intake which can lead to iodine induced hyperthyroidism. After iodine supplementation, the risk for iodine induced hyperthyroidism has been reported in some African countries [29]. Our data suggest that excess iodine intake may be increasing the prevalence of subclinical hyperthyroidism in the children while at the same time contributing for hypothyroidism. Iodine is a component of thyroid hormone, so it has crucial role in maintaining normal thyroid function [12]. Both iodine deficiency and excess can coexist in the different regions of same country and contribute towards thyroid disorders [30]. Furthermore, we observed high risk for thyroid dysfunction in the children who had thyroid autoimmunity, which indicates the impact of thyroid autoimmunity on thyroid dysfunction. In the regions with adequate iodine nutrition, thyroid autoimmunity becomes a significant factor for thyroid dysfunction [11].

We observed a strong association of iodine nutrition and thyroid autoimmunity in this study. This emphasizes the importance of maintaining proper iodine nutrition in children to prevent thyroid autoimmunity development. Here we used anti-Tg antibodies to define thyroid autoimmunity instead of anti-TPO antibodies, which is one of the limitations of this study. We were interested to assess anti-Tg antibodies level in Nepalese setting as there were no previous data on this antibodies. In addition, iodine deficient children had high risk for thyroid autoimmunity than children with adequate iodine nutrition. Several studies have showed low UIC as a risk factor for thyroidal autoimmunity in the population living in iodine sufficient areas $[31,32]$. At the same time, after the start of salt iodization program, several countries have reported rise in the incidence of thyroid autoimmunity possibly due to excess iodine nutrition [27, 33, 34]. A systematic review suggested that despite improvement in goiter rate through universal iodization, chronic intake of iodine through iodized salt or water increases risk for hypothyroidism in the population [35]. Thus it is important to monitor iodine intake and UIC in the 
population for minimizing thyroid autoimmunity and thyroid dysfunction. This study has several limitations such as small sample size that might have affected prevalence of thyroid autoimmunity including pattern of thyroid disorders, lack of anti-TPO antibodies for thyroid autoimmunity, and cross-sectional nature which cannot draw conclusion about cause and effect relationship between iodine deficiency, thyroid autoimmunity and thyroid dysfunction. Future studies need to be conducted covering larger areas and population, and should be directed towards finding the exact cause for this high rate of thyroid autoimmunity.

\section{Conclusions}

School children of eastern Nepal have adequate iodine nutrition. Thyroid dysfunction is sparse but thyroid autoimmunity is common in children. A strong association of thyroid autoimmunity with iodine nutrition and thyroid dysfunction was seen in this cohort.

\section{Abbreviations}

APDM: Ammonium persulphate digestion method; Free T3: Free triiodothyronine; Free T4: Free thyroxine; ID: lodine deficiency; Tg: Thyroglobulin; TgAb: Antithyroglobulin antibody; TPO: Thyroid peroxidase; TSH: Thyroid stimulating hormone; UIC: Urinary iodine concentration; USI: Universal salt iodization; VDC: Village development commitee; WHO: World health organization

\section{Acknowledgements}

We kindly acknowledge school children who participated in this study, and the school authorities for assisting the study.

\section{Authors' contributions}

BT, SK, BG and ML designed the study. BT, SK, BG conducted the field study. BT analyzed the samples. BT and SK analyzed the data and wrote the manuscript. BG, SS, KDM, NB, GSH and ML reviewed manuscript. All authors read and approved the final version of manuscript.

\section{Funding}

None.

\section{Availability of data and materials}

Data available from the authors on special request.

\section{Ethics approval and consent to participate}

The ethical approval for this study was provided by the Institutional Review Committee (IRC) of B P Koirala Institute of Health Sciences (BPKIHS), Dharan, Nepal. Consents to enroll in the study were taken from each child including their guardians.

\section{Consent for publication}

Not applicable.

\section{Competing interests}

he authors declare that they have no competing interests.

\section{Author details}

'Department of Biochemistry, Universal College of Medical Sciences, Bhairahawa, Nepal. ${ }^{2}$ School of Medical Sciences, UNSW SYDNEY, Sydney, Australia. ${ }^{3}$ Department of Biochemistry, B P Koirala Institute of Health Sciences, Ghopa, Dharan, Nepal. ${ }^{4}$ Department of Paediatrics and Adolescent medicine, B P Koirala Institute of Health Sciences, Dharan, Nepal.
Received: 29 April 2019 Accepted: 1 July 2019

Published online: 09 July 2019

\section{References}

1. Mullur R, Liu YY, Brent GA. Thyroid hormone regulation of metabolism. Physiol Rev. 2014;94(2):355-82. https://doi.org/10.1152/physrev.00030.2013.

2. Alemu A, Terefe B, Abebe M, Biadgo B. Thyroid hormone dysfunction during pregnancy: a review. Int J Reprod Biomed (Yazd). 2016;14(11):677-86.

3. Institute of Medicine (US) Committee on Medicare Coverage of Routine Thyroid Screening; Stone MB, Wallace RB, editors. Medicare coverage of routine screening for thyroid dysfunction. Washington (DC): National Academies Press (US); 2003.3, Prevalence and Consequences of Thyroid Dysfunction.

4. Baral N, Lamsal M, Koner BC, Koirala S. Thyroid dysfunction in eastern Nepal. Southeast Asian J Trop Med Public Health. 2002;33(3):638-41.

5. Mahato RV, Nepal AK, Gelal B, Poudel B, Yadav BK, Lamsal M. Spectrum of thyroid dysfunction in patients visiting Kantipur hospital, Kathmandu, Nepal. Mymensingh Med J. 2013;22(1):164-9.

6. Khatiwada S, Kc R, Sah SK, Khan SA, Chaudhari RK, Baral N, Lamsal M. Thyroid dysfunction and associated risk factors among Nepalese diabetes mellitus patients. Int J Endocrinol. 2015;2015:570198. https://doi.org/1 $0.1155 / 2015 / 570198$

7. Khatiwada S, Sah SK, Kc R, Baral N, Lamsal M. Thyroid dysfunction in metabolic syndrome patients and its relationship with components of metabolic syndrome. Clin Diabetes Endocrinol. 2016;2:3. https://doi.org/1 0.1186/s40842-016-0021-0.

8. Chaudhary LN, Khatiwada S, Gelal B, Gautam S, Lamsal M, Pokharel H, Baral $\mathrm{N}$. lodine and thyroid function status, and anti-thyroid peroxidase antibody among pregnant women in eastern Nepal. J Nepal Health Res Counc. 2017:15(2):114-9.

9. Khatiwada S, Gelal B, Baral N, Lamsal M. Association between iron status and thyroid function in Nepalese children. Thyroid Res. 2016;9:2. https://doi. org/10.1186/s13044-016-0031-0.

10. Shakya PR, Gelal B, Lal Das BK, Lamsal M, Pokharel PK, Nepal AK, Brodie DA, Sah GS, Baral N. Urinary iodine excretion and thyroid function status in school age children of hilly and plain regions of eastern Nepal. BMC Res Notes. 2015:8:374. https://doi.org/10.1186/s13104-015-1359-6.

11. Vanderpump MP. The epidemiology of thyroid disease. Br Med Bull. 2011:99:39-51. https://doi.org/10.1093/bmb/ldr030.

12. Chung HR. lodine and thyroid function. Ann Pediatr Endocrinol Metab. 2014;19(1):8-12. https://doi.org/10.6065/apem.2014.19.1.8.

13. Fröhlich $E$, Wahl R. Thyroid autoimmunity: role of anti-thyroid antibodies in thyroid and extra-thyroidal diseases. Front Immunol. 2017:8:521. https://doi. org/10.3389/fimmu.2017.00521.

14. Latrofa F, Fiore E, Rago T, Antonangeli L, Montanelli L, Ricci D, et al. lodine contributes to thyroid autoimmunity in humans by unmasking a cryptic epitope on thyroglobulin. J Clin Endocrinol Metab. 2013;98(11):1768-74 https://doi.org/10.1210/jc.2013-2912.

15. Ministry of Health and Population, Department of Health Services, Government of India and Alliance Nepal. National Survey and impact study for iodine deficiency disorders (IDD) and availability of iodized salt in Nepal; 2007

16. Khatiwada S, Gelal B, Gautam S, Lamsal M, Baral N. lodine status among school children of remote hilly regions of Nepal. Indian Pediatr. 2015;52(5):436-7.

17. Khatiwada S, Lamsal M, Gelal B, Gautam S, Nepal AK, Brodie D, et al. Anemia, Iron deficiency and iodine deficiency among Nepalese school children. Indian J Pediatr. 2016;83(7):617-21. https://doi.org/10.1007/s12098015-1924-y.

18. Khatiwada S, Gelal B, Shakya PR, Lamsal M, Baral N. Urinary iodine excretion among Nepalese school children in Terai region. Indian J Pediatr. 2016;83(1):15-7. https://doi.org/10.1007/s12098-015-1755-x.

19. Khatiwada S, Gelal B, Tamang MK, KC R, Singh S, Lamsal M, Baral N. lodized salt use and salt iodine content among household salts from six districts of eastern Nepal. J Nepal Health Res Counc. 2014;12(28):191-4.

20. Ohashi T, Yamaki M, Pandav CS, Karmarkar MG, Irie M. Simple microplate method for determination of urinary iodine. Clin Chem. 2000:46(4):529-36.

21. World Health Organization. Assessment of iodine deficiency disorders and monitoring their elimination: a guide for programme managers. 3rd ed. Geneva: World Health Organization; 2007. viii, 99 p. 
22. Zimmermann MB, Jooste PL, Pandav CS. lodine-deficiency disorders. Lancet. 2008;372(9645):1251-62.

23. Chaudhari RK, Gelal B, Brodie DA, Baral N. Thyroid function and urinary iodine status in primary school age children of the hills and the plains of eastern Nepal. Indian Pediatr. 2012;49(4):332-3.

24. Gelal B, Aryal M, Das BKL, Bhatta B, Lamsal M, Baral N. Assessment of iodine nutrition status among school age children of Nepal by urinary iodine assay. Southeast Asian J Trop Med Public Health. 2009;40:538-43.

25. Omar MS, El-Sayed Desouky D. Environmental, urinary iodine status and prevalence of goitre among schoolchildren in a high altitude area of Saudi Arabia. Pak J Med Sci. 2015;31(2):414-9. https://doi.org/10.12669/ pjms.312.6637.

26. Khalili N, Hashemipour M, Keshteli AH, Siavash M, Amini M. The role of thyroid autoantibodies in the etiology of endemic goiter in schoolchildren of Isfahan, Iran. J Endocrinol Investig. 2009;32(11):899-902. https://doi.org/1 $0.1007 / B F 03345769$.

27. Premawardhana $L D$, Parkes $A B$, Smyth PP, Wijeyaratne $C N$, Jayasinghe $A$, de Silva DG, et al. Increased prevalence of thyroglobulin antibodies in Sri Lankan schoolgirls-is iodine the cause? Eur J Endocrinol. 2000;143(2):185-8.

28. Franco JS, Amaya-Amaya J, Anaya JM. Thyroid disease and autoimmune diseases. In: Anaya JM, Shoenfeld Y, Rojas-Villarraga A, et al., editors. Autoimmunity: from bench to bedside [internet]. Bogota (Colombia): El Rosario University Press; 2013. Chapter 30. Available from: https://www.ncbi. nlm.nih.gov/books/NBK459466/.

29. Delange F, de Benoist B, Alnwick D. Risks of iodine-induced hyperthyroidism after correction of iodine deficiency by iodized salt. Thyroid. 1999;9(6):545-56.

30. Du Y, Gao Y, Meng F, Liu S, Fan Z, Wu J, Sun D. Iodine deficiency and excess coexist in China and induce thyroid dysfunction and disease: a crosssectional study. PLoS One. 2014;9(11):e111937. https://doi.org/10.1371/ journal.pone.0111937.

31. Chen C, Xu H, Chen Y, Chen Y, Li Q, Hu J, et al. lodized salt intake and its association with urinary iodine, thyroid peroxidase antibodies, and thyroglobulin antibodies among urban Chinese. Thyroid. 2017;27(12):1566-73. https:/doi.org/10.1089/thy.2017.0385.

32. Chen X, Chen L, Lian X, Liu C, Shan Z, Shi B, et al. Urinary iodine concentration is inversely associated with the thyroglobulin antibody. Endocr Pract. 2019. https://doi.org/10.4158/EP-2018-0252.

33. Palaniappan S, Shanmughavelu L, Prasad HK, Subramaniam S, Krishnamoorthy N, Lakkappa L. Improving iodine nutritional status and increasing prevalence of autoimmune thyroiditis in children. Indian Endocrinol Metab. 2017;21 (1):85-9. https://doi.org/10.4103/2230-8210.195996

34. Teng X, Shan Z, Chen Y, Lai Y, Yu J, Shan L, Bai X, et al. More than adequate iodine intake may increase subclinical hypothyroidism and autoimmune thyroiditis: a cross-sectional study based on two Chinese communities with different iodine intake levels. Eur J Endocrinol. 2011;164(6):943-50. https://doi.org/10.1530/EJE-10-1041.

35. Katagiri R, Yuan X, Kobayashi S, Sasaki S. Effect of excess iodine intake on thyroid diseases in different populations: a systematic review and metaanalyses including observational studies. PLoS One. 2017;12(3):e0173722. https://doi.org/10.1371/journal.pone.0173722.

\section{Publisher's Note}

Springer Nature remains neutral with regard to jurisdictional claims in published maps and institutional affiliations.

Ready to submit your research? Choose BMC and benefit from:
- fast, convenient online submission
- thorough peer review by experienced researchers in your field
- rapid publication on acceptance
- support for research data, including large and complex data types
- gold Open Access which fosters wider collaboration and increased citations
- maximum visibility for your research: over 100M website views per year
At BMC, research is always in progress.
Learn more biomedcentral.com/submissions

